\title{
NOTES
}

\section{Enantioselective Oxidation Catalyzed by Manganese(III)- Tetraphenylporphyrin-Bovine Serum Albumin Systems Modified or Unmodified with Poly(ethylene glycol)}

\author{
Kohji Yoshinaga, ${ }^{*}$ Naoki IтOH, and Taketoshi Kito \\ Department of Applied Chemistry, Kyushu Institute of Technology, \\ Sensui, Tobata-ku, Kitakyushu 804, Japan
}

(Received June 27, 1990)

\begin{abstract}
KEY WORDS Protein Hybrid / Metalloporphyrin / Bovine Serum Albumin
/ Asymmetric Oxidation / Poly(ethylene glycol) / Chemical Modification /
\end{abstract}

Protein hybrid recently becomes of much interest in therapeutics, ${ }^{1}$ enzymology, ${ }^{2}$ and biotechnology. ${ }^{3}$ In our previous works, ${ }^{4,5}$ we have coupled the manganese(III)-tetraphenylporphyrin complex to bovine serum albumin (BSA), which provides a chiral reaction field, in order to approach to an artificial tryptophan dioxygenase, and shown that the hybrid catalytic system has exhibited the activity for stereoselective dioxygenation of methyl $\mathrm{N}$-acetyl-L-(or D-)tryptophanate with molecular oxygen, involving the indole-ring cleavage. Moreover, it was found out that attachment of poly(ethylene glycol) (PEG) to the BSA hybrid catalyst prevented from deformation even in aqueous solvent containing $60 \mathrm{vol} \%$ of tetrahydrofuran (THF) ${ }^{5}$

On the other hand, metalloporphyrins, widely studied as models of hemes or cytochrome P-450, have been also known to exhibit the catalytic activity for monooxygenation, proceeding via the formation of high valency metal-oxygen complex intermediate. ${ }^{6}$

In this work, we have examined asymmetric epoxidation of olefins and oxidation of sufides by the Mn(III) CITPP-BSA hybrid catalytic systems, and effects of PEG modification on their activities and enantioselectivities.

\section{EXPERIMENTAL}

\section{Materials}

BSA (Fraction V) and poly(ethylene glycol) monomethyl ether of molecular weight of 5000 were purchased from Sigma Chemical and Aldrich Chemical Co., respectively. Complexes of 5, 10, 15, 20-tetraphenylporphyrin manganese (III) chloride (MnClTPP) and 5, 10, 15, 20-tetrakis ( $p$-carboxyphenyl)porphyrin manganese (III) chloride (MnClTCPP) were prepared by the literature method. ${ }^{7}$ Thioacetic acid esters were synthesized by the method of Newell et al. ${ }^{8}$

\section{Preparation of $\mathrm{MnClTCPP}-\mathrm{BSA}$}

MnClTCPP $N$-hydroxysuccinimidyl monoester was prepared from equimolar $N$ hydroxysuccinimide with the manganese complex using dicyclohexylcarbodiimide in $N, N$ dimethylformamide. A mixture of the monoester $(17 \mathrm{mg}, 0.02 \mathrm{mmol})$ and BSA $(0.345 \mathrm{~g}$, $\left.5 \times 10^{-3} \mathrm{mmol}\right)$ in $\mathrm{pH} 9.3$ buffer $\left(0.05 \mathrm{moll}^{-1}\right.$ $\mathrm{Na}_{2} \mathrm{~B}_{4} \mathrm{O}_{7}$ ) was stirred at $4^{\circ} \mathrm{C}$ over day. Unbound manganese complex was removed by a gel filtration (Sephadex G-50), followed by a ultrafiltration (Toyo Roshi UK-50) with 0.05

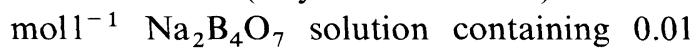

\footnotetext{
* To whom all correspondance should be addressed.
} 
moll-1 $\mathrm{NaN}_{3}$. A unit gram of BSA loaded $60 \mathrm{mg}\left(6.9 \times 10^{-2} \mathrm{mmol}\right)$ of MnClTCPP, which was determined by the absorbance of Soret bands $\left(\varepsilon=5.44 \times 10^{4} \mathrm{~mol}^{-1} 1 \mathrm{~cm}\right)$ at $467 \mathrm{~nm}$ with spectrophotometry.

\section{PEG Attachment to MnClTCPP-BSA}

To $10 \mathrm{ml}$ of the borate buffer solution containing approximate $100 \mathrm{mg}$ of $\mathrm{MnClTCPP}$ BSA was added $100 \mathrm{mg}$ of methoxypolyethylene glycolyl $N$-succinimidyl succinate, prepared by the method of Abuchowski et al., ${ }^{9}$ and the mixture was kept stirring for $2 \mathrm{~h}$ at $4^{\circ} \mathrm{C}$. Unreacted PEG was removed with the ultrafiltration. It was determined that PEG attached to $33 \%$ of amino groups (mainly lysine residue) of BSA, by means of Habeeb's method $^{10}$ using PEG-attached BSA derived from the same amount of BSA and the activated PEG under the same condition as in the preparation of MnCITCPP-BSA-PEG.

\section{Epoxidation of Olefins}

A typical run was carried out as follows. To a mixture of MnCITCPP-BSA $(0.1 \mathrm{~g})$ in the borate buffer $(2 \mathrm{ml})$ and styrene $(1.5 \mathrm{~g}$, $14 \mathrm{mmol})$ in $\mathrm{CHCl}_{3}(10 \mathrm{ml})$ were added $15 \mathrm{ml}$ of $\mathrm{NaOCl}$ aqueous solution (35\%) and $3 \mathrm{ml}$ of

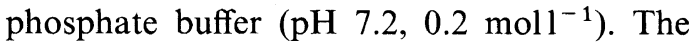
resulting solution was magnetically kept stirring at $25^{\circ} \mathrm{C}$ for 2 days. Extraction with three portions of chloroform $(50 \mathrm{ml}$ each) and evaporation gave the crude product, which was purified by chromatography on silica gel with hexane and successively chloroform-hexane $(50: 50 \mathrm{vol} \%)$. After determination of styrene oxide by gas chromatography, its chloroform solution was subjected to optical rotation measurement. In the same procedure using racemic styrene oxide instead of styrene, it was confirmed that recovered styrene oxide included no optically active contaminants of BSA or its decomposed products.

\section{Oxidation of Sulfides}

A mixture of sulfide $(0.8 \mathrm{~g})$ in organic solvent
$(2 \mathrm{ml})$ and the borate buffer $(2 \mathrm{ml})$ containing MnClTCPP-BSA $(0.1 \mathrm{~g})$ was charged in a flask and stirred for $2 \mathrm{~h}$ at $25^{\circ} \mathrm{C}$, and $6 \mathrm{ml}$ of hydrogen peroxide aqueous solution $(31 \%)$ and $2 \mathrm{ml}$ of the phosphate buffer were added. After stirring at $25^{\circ} \mathrm{C}$ for 1 or 2 days, the sulfoxide produced was separated from the reaction mixture in a similar manner as described previously, except for the use of hexane and successively diethyl ether-hexane $(80: 20 \mathrm{vol} \%)$ as eluent in chromatography.

\section{RESULTS AND DISCUSSION}

Catalytic oxidation or epoxidation of olefinic compounds with metalloporphyrin complexes was usually carried out using a proper oxidant, such as $\mathrm{NaOCl}$ or $\mathrm{NaIO}_{4}$, in the presence of surfactant as a phase transfer medium. ${ }^{11}$ When a mixture of styrene and $\mathrm{MnClTPP}$ in $\mathrm{CH}_{2} \mathrm{Cl}_{2}$ or $\mathrm{CHCl}_{3}$ was stirred together with the phosphate buffer ( $\mathrm{pH}$ 7.2) solution of BSA and with $\mathrm{NaOCl}$ aqueous solution for 4 days, optically active styrene oxide in enantiomeric excess (e.e.) of $3.6-4.8 \%$, was produced in yield of $80-85 \%$ accompanied with benzaldehyde formation in the range of $2-3 \%$ yield (Table I). The catalytic reaction in the absence of BSA afforded small amount of styrene oxide in yield of $3.5 \%$ for 1 day. Thus, BSA possibly works as both roles of a phase transfer medium and a chiral reaction field, while the reaction by $\mathrm{MnClTPP} / \mathrm{BSA}$ catalyst (prepared in situ) proceeded slower than that by MnCITPP in the presence of surfactant such as $N, N, N$ trimethylbenzylammonium bromide. It has been reported that the surfactant-mediated reaction is usually involved with the formation of an ion pair $\left(\equiv \mathrm{N}^{+} \mathrm{ClO}^{-}\right)$and with its movement from aqueous phase to organic phase, followed by the production of $\mathrm{Mn}(\mathrm{O})$ CITPP complex. ${ }^{6}$ On the contrary in the present reaction system, BSA, mostly existing in aqueous phase in the reaction mixture, might trap MnClTPP and the substrate on the interface of two phases, and then transfer them 
Table I. Epoxidation of styrene by in situ prepared MnClTPP/BSA (I), MnClTCPP-BSA (II) and $\mathrm{MnClTCPP}-\mathrm{BSA}-\mathrm{PEG}$ (III) at $25^{\circ} \mathrm{C}$ at $\mathrm{pH} 7.2^{\circ}$

\begin{tabular}{|c|c|c|c|c|c|}
\hline \multirow{2}{*}{ Cat. } & Org. solv. & Time & Yield & {$[\alpha]_{\mathrm{D}}^{23}$} & e.e. ${ }^{\mathrm{b}}$ \\
\hline & vol \% & day & $\%$ & deg & $\%$ \\
\hline $\mathrm{I}^{\mathrm{c}}$ & $\mathrm{CHCl}_{3}$ (33) & 4 & 85 & 1.2 & 4.8 \\
\hline$I^{c}$ & $\mathrm{CH}_{2} \mathrm{Cl}_{2}(33)$ & 4 & 79 & 0.9 & 3.6 \\
\hline$I^{d}$ & $\mathrm{CH}_{2} \mathrm{Cl}_{2}(33)$ & 2 & 81 & 1.2 & 4.8 \\
\hline $\mathrm{I}^{\mathrm{c}}$ & THF $\quad(10)$ & 1 & 85 & 2.4 & 9.6 \\
\hline $\mathrm{I}^{\mathrm{e}}$ & THF $\quad(10)$ & 1 & 24 & 0 & 0 \\
\hline $\mathrm{I}^{\mathrm{c}}$ & THF (17) & 1 & 54 & 2.2 & 8.8 \\
\hline II $^{\mathrm{f}}$ & $\mathrm{CHCl}_{3}$ & 4 & 87 & 1.2 & 4.8 \\
\hline $\mathrm{II}^{\mathrm{f}}$ & THF $\quad(10)$ & 4 & 92 & 2.9 & 11.7 \\
\hline III $^{\mathrm{f}}$ & $\mathrm{CHCl}_{3}$ & 4 & 92 & 1.0 & 4.0 \\
\hline
\end{tabular}

a Styrene, $1.5 \mathrm{~g} ; \mathrm{NaOCl}$ solution, $15 \mathrm{ml}$.

b Calculated from $[\alpha]_{\mathrm{D}}^{23}-24.89^{\circ}\left(c 2.86 \text { in } \mathrm{CHCl}_{3}\right)^{13}$ for (R)-styrene oxide.

c From $30 \mathrm{mg}$ of MnClTPP and $30 \mathrm{mg}$ of BSA.

d From $30 \mathrm{mg}$ of MnClTPP and $30 \mathrm{mg}$ of BSA-PEG.

e From $30 \mathrm{mg}$ of MnClTPP in the absence of BSA.

f Consisted of $6 \mathrm{mg}$ of MnClTCPP and $0.1 \mathrm{~g}$ of BSA.

to the aqueous phase to react with $\mathrm{OCl}^{-}$. Indeed, efficient and rapid inclusions of MnCITPP and a hydrophobic compound, such as methyl $N$-acetyl-L-tryptophanate, into BSA in a few minutes after mixing were observed by absorbance changes at $468 \mathrm{~nm}$ (Soret bands) and $B$ bands at $280 \mathrm{~nm}$, respectively, on spectrophotometric spectra. ${ }^{4}$

Meanwhile, PEG modification of protein sometimes improves solubility and/or affinity in organic solvents, hence we have examined the reaction using the PEG-modified BSA. As shown in Table I, an increase of the reaction rate due to PEG modification was observed, but the enantioselectivity was not affected. These results suggest that PEG attached on BSA contributes to only the phase transfer process, not to the asymmetric induction process.

The MnClTCPP-BSA catalytic systems modified and unmodified by PEG did not substantially improve the asymmetric selectivity as compared with the catalytic systems (I in Table I) prepared in situ. Probably, the low enantioselectivity comes from difficulty of rigid coordination of styrene to hydrophobic binding sites of BSA, because of unfunctionalized substrate. Interestingly, $\mathrm{THF}-\mathrm{H}_{2} \mathrm{O}$ solvent system gave slightly higher e.e. $(8-12 \%)$ of styrene oxide than $\mathrm{CHCl}_{3}$ or $\mathrm{CH}_{2} \mathrm{Cl}_{2}-\mathrm{H}_{2} \mathrm{O}$ heterogeneous solvent system. Water-miscible solvents sometimes remarkably deform protein due to removal of liganded water molecules sustaining the secondary and tertiary structure. ${ }^{12}$ Indeed, we have observed that BSA is deformed in THF (30 vol\%)- $\mathrm{H}_{2} \mathrm{O}$ system day by day and more quickly in the solvent containing $60 \mathrm{vol} \%$ of THF hour by hour. ${ }^{5}$ In the heterogeneous system, the BSA hybrid catalyst exists in aqueous phase, so that the conformation of BSA is considered to be retained. Therefore, following two explanations can be considered concerning the solvent effects on the catalytic enantioselectivity: (1) hydrophilic circumstance of $\mathrm{THF}-\mathrm{H}_{2} \mathrm{O}$ system gives more rigid coordination of styrene to the binding site of BSA through hydrophobic interaction, and (2) BSA conformation deformed in the aqueous solvent is favorable for the enantio-face selective coordination of styrene. In this case, the former seems to be plausible.

Another olefinic compounds besides styrene, such as trans-stilbene, $\alpha$-methylstyrene, ethyl cinnamate, gave a few inseparable byproducts, although the formation of corresponding oxides was recognized.

We next examined asymmetric oxidation of sulfides, which have polar groups to be expected to take rigid coordination to the BSA hybrid catalytic system, using hydrogen peroxide as an oxidant. By preliminary experiments, it was shown that comparatively strong oxidants, such as $\mathrm{NaOCl}$ and $m$-chloroperbenzoic acid, were inadequate for this reaction, because of bringing about rapid spontaneous oxidation of sulfides used. As seen in Table II, the sulfoxides produced from phenyl methyl sulfide and 1-(phenylthio)acetic acid esters showed extremely low optical 
Table II. Oxidation of sulfides $\left(\mathrm{R}^{1}-\mathrm{O}-\mathrm{S}\right.$ $\mathrm{CH}_{2} \mathrm{COOR}^{2}$ ) by II and III at $25^{\circ} \mathrm{C}$ at $\mathrm{pH} 7.2^{\mathrm{a}}$

\begin{tabular}{|c|c|c|c|c|c|c|c|c|}
\hline \multicolumn{2}{|c|}{ Sulfide } & \multirow{2}{*}{ Cat. } & \multicolumn{2}{|c|}{ Org. solv. } & \multirow{2}{*}{$\frac{\text { Time }}{\text { day }}$} & \multirow{2}{*}{$\frac{\text { Yield }}{\%}$} & \multirow{2}{*}{$\frac{[\alpha]_{D}^{23}}{\operatorname{deg}}$} & \multirow{2}{*}{$\frac{e . e .}{\%}$} \\
\hline $\mathbf{R}^{1}$ & $\mathrm{R}^{2}$ & & vol $\%$ & & & & & \\
\hline $\mathrm{H}$ & $\mathrm{Me}$ & II & & $(0)$ & 1 & 68 & -0.3 & \\
\hline $\mathrm{H}$ & $\mathrm{Bu}$ & II & & (0) & 2 & 37 & 1.5 & \\
\hline \multirow[t]{5}{*}{$\mathrm{Me}$} & $\mathrm{Me}$ & II & & (0) & 1 & 92 & 3.7 & $<5^{\mathrm{b}}$ \\
\hline & & II & THF & (17) & 1 & 94 & 5.2 & $7^{\mathrm{b}}$ \\
\hline & & II & $\mathrm{CH}_{3} \mathrm{CN}$ & (17) & 1 & 96 & 0.9 & \\
\hline & & III & THF & (17) & 1 & 81 & 4.1 & $<5^{\mathrm{b}}$ \\
\hline & & III & $\mathrm{CHCl}_{3}$ & (17) & 1 & 30 & 3.1 & $<5^{\mathrm{b}}$ \\
\hline \multirow[t]{6}{*}{$\mathrm{Me}$} & $\mathrm{Ph}$ & II & & (0) & 3 & 71 & 9.7 & $5.4^{\mathrm{c}}$ \\
\hline & & II & THF & (17) & 3 & 15 & 10 & $5.5^{\mathrm{c}}$ \\
\hline & & II & $\mathrm{CHCl}_{3}$ & (33) & 2 & 89 & 9.1 & $5.0^{\mathrm{c}}$ \\
\hline & & & $\mathrm{CHCl}_{3}$ & $(33)^{d}$ & 2 & 62 & 0.5 & $0.3^{\mathrm{c}}$ \\
\hline & & III & THF & (17) & 2 & 25 & 9.4 & $5.2^{\mathrm{c}}$ \\
\hline & & III & $\mathrm{CHCl}_{3}$ & (33) & 2 & 79 & 13 & $7.2^{\mathrm{c}}$ \\
\hline
\end{tabular}

a Sulfide, $0.8 \mathrm{~g}$; hydrogen peroxide solution $(31 \%), 6 \mathrm{ml}$.

b Determined by ${ }^{1} \mathrm{H}$ NMR with $\mathrm{Eu}(\mathrm{hfc})_{3}$ as a shift reagent.

c Calculated from $[\alpha]_{\mathrm{D}}+180.9^{\circ}\left(c 1 \text { in } \mathrm{CHCl}_{3}\right)^{14}$ for (R)-(+)-phenyl 1-(p-tolylsulfinyl)acetate.

d In the presence of only BSA $(0.1 \mathrm{~g})$.

rotation, although asymmetric induction was recognized. The oxidation of 1-( $p$-tolylthio)acetate derivatives catalyzed by MnClTCPPBSA complexes gave the optically active sulfoxide in low but reproducible e.e. (5-7\%). The polar solvent of $\mathrm{CH}_{3} \mathrm{CN}-\mathrm{H}_{2} \mathrm{O}$ system effected on the reaction rate, but markedly suppressed the enantioselectivity. The bulky phenyl ester group retarded the reaction, as compared with the methyl group, but did not unexpectedly bring about an increase of e.e. of the sulfoxide. It is also notable that the reaction in heterogeneous solvent system of $\mathrm{CHCl}_{3}$ $\mathrm{H}_{2} \mathrm{O}$ proceeded faster than that in homogeneous THF- $-\mathrm{H}_{2} \mathrm{O}$ system, in opposite phenomena in the epoxidation of styrene. In this case, the retained conformation of BSA in the heterogeneous system might be favorable for inclusion of the sulfide of phenyl ester. The effectiveness of PEG-modification of BSA was realized in the reaction in $\mathrm{THF}-\mathrm{H}_{2} \mathrm{O}(17 \mathrm{vol} \%$ THF); increased yield of the product from $15 \%$ for 3 days to $25 \%$ for 2 days. However, it was observed that the oxidation catalyzed by $\mathrm{MnClTCPP}-\mathrm{BSA}$ in $\mathrm{CHCl}_{3}-\mathrm{H}_{2} \mathrm{O}$ system was involved with spontaneous reaction in considerable extent; about $50 \%$ conversion under the condition shown in Table II. Also, the reaction in the presence of only $\mathrm{BSA}$ in $\mathrm{CHCl}_{3}$ (33 vol\%) $-\mathrm{H}_{2} \mathrm{O}$ for 2 days resulted in formation of the sulfoxide in $0.3 \%$ e.e. and in $62 \%$ yield, which corresponds to about $70 \%$ of the product yield in the MnCITCPP-BSA catalyzed reaction. Therefore, it is suggested that the BSA hybrid catalysts participate in the asymmetric induction during the oxidation, and also e.e.'s of sulfoxides produced by net catalytic reaction are approximately two or three times higher than values shown in Table II. Inhibition of the spontaneous oxidation and details in the present reaction are now under investigation.

\section{REFERENCES}

1. Y. Ikada, Biomedica, 3, 1154 (1988).

2. Y. Inada, K. Takahashi, T. Yoshimoto, Y. Kodera, A. Matsushima, and Y. Saito, Trends Biotechnol., 6, 131 (1988)

3. D. Fisher and L. A. Sutherland, "Separation Using Aqueous Phase Systems; Applications in Cell Biology and Biotechnology," Plenum, London, 1989.

4. K. Ohkubo, H. Ishida, K. Yoshinaga, T. Sagawa, K. Urabe, M. Moriyasu, and H. Sone, Polym. Prepr., Jpn., 39, 824 (1990).

5. K. Ohkubo, H. Ishida, K. Yoshinaga, T. Sagawa, and K. Urabe, Polym. Prepr., Jpn., 39, 825 (1990).

6. R. H. Holm, Chem. Rev., 87, 1401 (1987).

7. A. Harriman and G. Porter, J. Chem. Soc., Faraday Trans. 2, 75, 1532 .(1979).

8. O. Newell and P. K. Calaway, J. Am. Chem. Soc., 69, 116 (1949).

9. A. Abchowski, G. M. Kazo, C. R. Verhoest, Jr, T. Van Es., D. Kafkewitz, M. L. Nucci, A. T. Vian, and F. F. Davis, Cancer Biochem. Biophys., 7, 175 (1984).

10. A. F. S. A. Habeeb, Anal. Biochem., 14, 328 (1966).

11. J. H. Ramsden, R. S. Drago, and R. Riley, J. Am. Chem. Soc., 111, 3958 (1989).

12. M. Waks, Proteins, 1, 4 (1986).

13. J. Biggs, N. B. Chapman, and V. Wray, J. Chem. Soc. B., 71 (1971).

14. R. Annunziata, M. Cinquini, and F. Cozzi, J. Chem. Soc., Perkin Trans. 1, 1687 (1979). 